\title{
Anamorfismos e o Teorema de Tales: uma proposta didática
}

\section{Anamorphisms and the Tales Theorem: a didactic proposal}

\author{
Jonathan de Aquino da Silva(jhonnymtm@gmail.com) \\ Universidade Franciscana \\ Carmen Vieira Mathias(carmen@ufsm.br) \\ Universidade Federal de Santa Maria \\ José Carlos Pinto Leivas (leivasjc@ufn.edu.br) \\ Universidade Franciscana
}

\begin{abstract}
Resumo:
A partir do momento em que se estuda Geometria na escola e, estando ciente de que fórmulas e expressões matemáticas não têm aplicabilidade sem uma compreensão do que se está estudando, no trabalho aqui apresentado visou-se analisar livros didáticos no intuito de verificar como é apresentado o Teo rema de Tales, suas demonstrações e aplicações. Além disso, foi criada e implementada uma proposta didática baseada no estudo de anamorfismos e sua relação com o Teorema. A aplicação da proposta pôde fazer com que o Teorema de Tales pudesse ser percebido em situações surpreendentes para os alunos, e a construção dos anamorfismos fez com que o espírito criativo e o trabalho em equipe dos alunos viessem à tona, ao mesmo tempo em que foi possível dar significado ao Teorema estudado.
\end{abstract}

Palavras-chave: geometria; anamorfismos; teorema de Tales; livros didáticos.

\begin{abstract}
:
From the moment studying geometry in school and being aware that mathematical formulas and expressions have no applicability without an understanding of what is being studied, the work presented here aimed to analyze textbooks in order to see how shows the Tales theorem, his demonstrations and applications. Also, it was created and implemented an didatical proposal based onanamorphisms study and its relationship with the theorem. Implementation of the proposal may cause the Tales theorem could be perceived in surprising situations for the students and the construction of anamorphisms made the creative spirit and the work of students team come to the fore, while it was possible to meaning the studied theorem.
\end{abstract}

Keywords: geometry; anamorphisms; Thales theorem; textbooks. 


\section{INTRODUÇÃ̃O}

No Brasil, conforme Freitag, Motta e Costa (1987), as iniciativas para garantir a distribuição de obras de interesse educacional tiveram origem com a criação do Instituto Nacional do Livro (INL), órgão subordinado ao Ministério da Educação e Cultura (MEC). A coordenação do livro didático fazia parte da estrutura do INL. "Competia a essa coordenação: planejar as atividades relacionadas com o livro didático e estabelecer convênios com órgãos e instituições que assegurassem a produção e distribuição do livro didático (FREITAG, 1985a, p. 134 apud FREITAG; MOTTA; COSTA,1987, p.6).

Segundo Núñez et al. (2003), já nessa época, o livro era caracterizado como uma ferramenta política e ideológica para a educação, sendo o Estado o censor no uso desse material didático. Os educadores escolhiam os livros que seriam utilizados a partir de uma lista pré-determinada na base dessa regulamentação legal.

Nos dias atuais, o programa responsável por avaliar e disponibilizar obras didáticas e outros materiais de apoio à prática educativa às escolas públicas de educação básica das quatro esferas (federal, estadual, municipal e distrital) é o Programa Nacional do Livro e do Material Didático (PNLD). Esse é mantido pelo Fundo Nacional de Desenvolvimento da Educação (FNDE), com recursos financeiros do Orçamento Geral da União (BRASIL, 2017)

A partir do PNLD,

[...] adotou-se um processo de análise para a aquisição dos livros a serem distribuídos e, a cada três anos, é lançado um edital com os critérios estabelecidos a fim de que os detentores dos direitos autorais inscrevam as obras didáticas. O processo de avaliação conta com a participação das universidades, uma vez que envolve livros de todas as disciplinas do currículo da educação básica. Ao final do processo de avaliação, é elaborado o Guia dos Livros Didáticos contendo resumo das obras para que os professores das escolas procedam à escolha dos livros a serem adotados (ROSA; ODDONE, 2006, p.191).

Observa-se que é recomendada, pelo PNLD, a participação democrática do professorno processo de seleção dos materiais didáticos. Essa circunstância estabelece que o docente tenha competência, prudência eseja crítico, no sentido de realizar, com o auxílio de seus pares, a escolha do livro didático a ser adotado na escola em que atua. 
A partir dessa ideia, houve a preocupação do segundo autor, de trabalhar, em um curso de mestrado profissional destinado à formação continuada de professores de Matemática, uma disciplina que teve como foco a análise crítica de materiais didáticos. Nessa disciplina, os alunos foram incentivados a pensar sobre o conhecimento matemático necessário para desenvolver determinado conteúdo no ensino básico; analisar, seguindo parâmetros determinados, como esse conteúdo era desenvolvido em livros didáticos e realizar uma proposta alternativa para ensinar o tópico escolhido.

Nesse contexto particular, pensando no ensino de Geometria no ensino básico, os conteúdos abrangem um campo imenso e, em algunslivros didáticos, os principais conceitos são pouco explorados e outros ainda podem ser trabalhados equivocadamente. Tal afirmação é subsidiada pelos Parâmetros Curriculares Nacionais: matemática, ao afirmar que "Decorrentes dos problemas da formação de professores, as práticas na sala de aula tomam por base os livros didáticos, que, infelizmente, são muitas vezes de qualidade insatisfatória” (BRASIL, 1997, p.22).

Assim, o presente artigo tem como objetivo analisar livros didáticos no intuito de verificar como é realizado o estudo do Teorema de Tales, suas demonstrações e aplicações; apresentarum recorte do trabalho desenvolvido como tema de uma dissertação de mestrado profissional do primeiro autor. Nessa, foi desenvolvida e implementada uma proposta didática alternativa para trabalhar Teorema de Tales na educação básica, visto que esse é um conteúdo que não possui muitas aplicações práticas. Assim, a aplicação desenvolvida utilizou anamorfismos, que são figuras com deformações podendo ser visualizadas com perfeição, desde que observadas de um ponto específico.

\section{SOBRE ANAMORFISMOS}

O conceito de anamorfismo, segundo o Dicionário Priberam da Língua Portuguesa, é "a representação ou imagem que parece deformada ou confusa e que se apresenta mais regular ou mais perceptível em determinado ângulo ou posição ou ainda por meio de lente ou espelho não plano" (PRIBERAM, 2010).Também foi encontrada a seguinte definição: 
O termo anamorfose (anamorfismo) (do grego anamorfosis- reformação, retorno à forma, reiteração da forma, reversão da forma [...], formar de novo, [...]), é utilizado em várias áreas do conhecimento - matemática, óptica (com aplicações nas artes visuais), biologia e geologia, com diferentes concepções. Assim sendo, o conceito de anamorfose difere de área para área (COELHO, 2018, p. 18).

A palavra também pode trazer um sentido de transformação e é utilizada em inúmeras áreas, como na matemática, artes, ótica, biologia, geologia e cartografia. Em particular nas artes, os anamorfismos são utilizados para forçar o observador a se colocar sob um determinado ponto de vista. Na óptica, os anamorfismos são encontrados quando a ampliação no sentido horizontal das imagens é diferente da ampliação em sentido vertical. Na geologia, os anamorfismos são usados para indicar fenômenos de formação de rochas de composição complexa por meio de mudanças na estrutura de outros minerais de composição mais simples, sejam elas pela ação de agentes físicos, como a pressão ou o calor, ou pela introdução de novas substâncias químicas (FLORES; ARAUJO; FIGUEIREDO, 2017).

As figuras anamórficas podem ser encontradas em muitos lugares (mesmo que passem despercebidas). Isso acontece porqueo ângulo de visão sobre a figura é distorcido. Exemplos são algumas propagandas percebidas em campos de futebol (Figura 1). Nesse caso, quando vistas pelos torcedores, da arquibancada, parecem placas apoiadas na grama, gerando certa ilusão óptica.

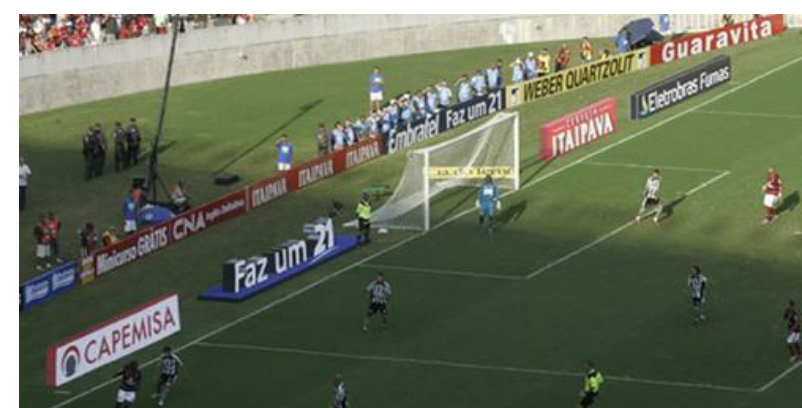

Figura 1 - Propagandas no campo de futebol.

Fonte: (MOTA, 2011)

Esse tipo de ilusão pode ser percebida em experimentos com arquitetura e tipografia, como é o caso ilustrado na Figura 2. 


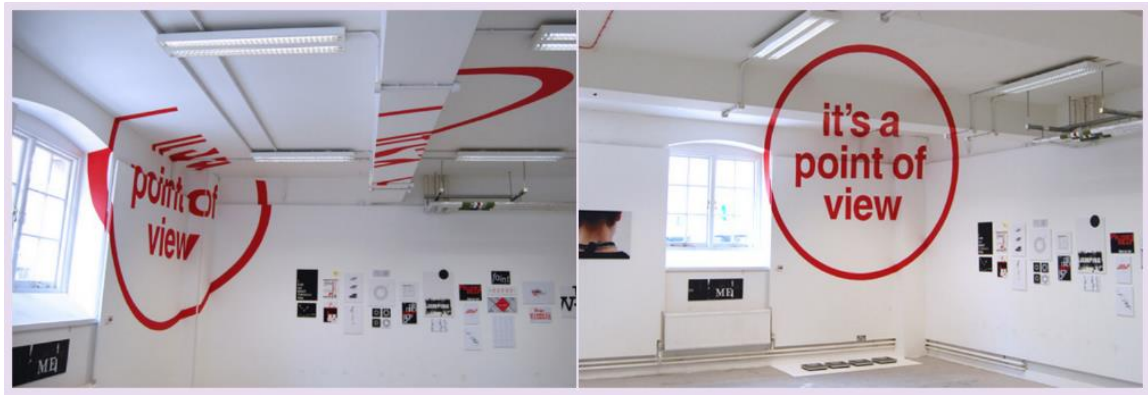

Figura 2 -Anamorfismo e Tipografia.

Fonte:(MOTA, 2011)

Acredita-se que uma das mais interessantes aplicações dos anamorfismos consiste das placas de sinalização de trânsito (Figura 3).

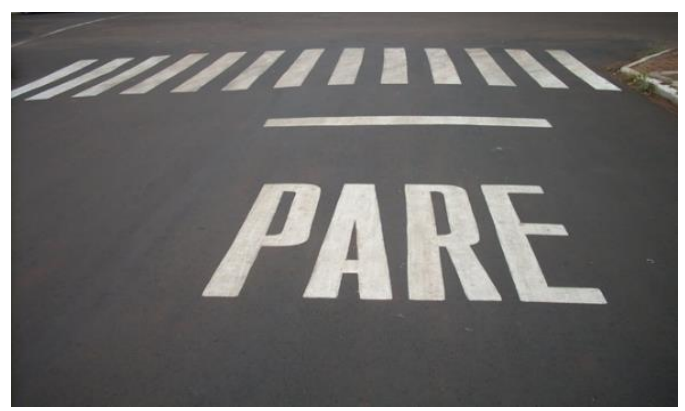

Figura 3 - Sinalização de trânsito.

Fonte: (IAVORSKI, 2014).

Pode-se, por exemplo, questionar por qual motivo as letras, as setas e os símbolos da palavra PARE, na Figura 3, estão desproporcionais e alongados verticalmente. Algunsdos possíveis motivos a responderem tal questionamento são: o solo está em um plano oblíquo em relação à visão do motorista; a leitura só se daria com maior clareza quando o motorista já estivesse muito próximo da mensagem. Portanto, quanto mais alongada for a mensagem, mais satisfatóriaserá a leitura de uma distância maior.A ideia utilizada na sinalização de trânsito pode ser pensada no sentido de deformar mensagens. Nesse sentido,Iavorski(2014) propõe uma atividade cujo objetivo é construir anamorfimospor meio da distorção de duas palavras sobrepostas, uma no sentido vertical e a outra, no sentido horizontal. Essa ilusão será muito importante na aplicação que será apresentada neste trabalho.

\section{PROCEDIMENTOS METODOLÓGICOS}


Neste estudo, são retomados conceitos importantes no campo da Geometria Euclidiana Plana, com abordagem direta, trazendo aplicações à realidade do aluno a partir de revisão de literatura, análise de livros didáticos, dentre outros. Assim, explorar e interpretar a linguagem que o livro e os materiais didáticos apresentam em Matemática precisam levar em consideração a compreensão dos conceitos envolvidos. Para Danyluk (2002, p. 18, apud BELLO E MAZZEI, 2016, p. 119), “a leitura, quando é compreensão, abre para o leitor novas possibilidades de compreensão de si, do outro e do mundo".

Classifica-se, portanto, esta pesquisa como qualitativa quanto a sua natureza, pois, de acordo com Bicudo (2004, p. 99), "No senso comum, o qualitativo é entendido como o oposto do quantitativo. Um falando de qualidade e tendo a ver com o subjetivo, com o sentimento, com opiniões acerca das coisas do mundo. O outro, quantificando aspectos objetivos sobre essas mesmas coisas".

O trabalho realizado dividiu-se em dois momentos distintos. Inicialmente, desenvolveu-se a análise dos livros e elaboração da proposta alternativa e, em um segundo momento, a aplicação da proposta.

É importante que os professores pensem sobre a escolha do livro didático a ser adotado. Em particular, em curso de pós-graduação em nível de mestrado, foi proporcionada, a professores em exercício, uma experiência refere ao tema, na disciplina denominada Tópicos de Matemática. O objetivo das aulas foi desenvolver a habilidade de analisar criticamente livros escolares para o ensino básico, bem como criar atividades alternativas àquelas apresentadas nos materiais analisados.

A proposta de análise de material didático não se limitava apenas à verificação dos conteúdos nos livros, mas consistia de cinco fases distintas: justificativa, expectativa, investigação do material, fundamentação matemática e proposta didática, as quais foram sugeridas pela professora da disciplina e que deveriam ser levadas em consideração pelos alunos.

No primeiro momento da pesquisa, foi realizada a escolha do tema e a justificativa. Também foram explanadas as expectativas sobre o conteúdo para o ano 
escolhido, juntamente com as expectativas de conteúdos para os livros didáticos. Após essa etapa, deu-se a análise, propriamente dita, dos materiais escolhidos.

A seleção dos livros didáticos de Matemática foi realizada a partir uma pesquisa feita com professores que atuam na rede estadual do ensino fundamental, no município onde a proposta foi implementada. Esse critério foi utilizado porque a maioria dos alunos, aos quais a proposta alternativa foi aplicada, são oriundos de escolas estaduais. A consulta aos profissionais foi realizada por meio de uma visita e uma entrevista informal. Conforme Gil(2002),

(...) entre todas as técnicas de interrogação, a entrevista é a que apresenta maior flexibilidade. Tanto é que pode assumir as mais diversas formas. Pode caracterizar-se como informal, quando se distingue da simples conversação apenas por ter como objetivo básico a coleta de dados (GIL, 2002, p.117).

Optou-se por esse tipo de entrevista pelo número reduzido de professores entrevistados (apenas dois).

Tendo o tópico Teorema de Tales como conteúdo balizador, analisou-se Bianchini (2015) e Andrini e Vasconcelos (2015), denominados respectivamente de livros A e B. Para a análise, foram considerados os seguintes eixos norteadores: Conteúdo matemático; Ilustrações; Atividades Propostas. A partir desses eixos, foram delimitados os parâmetros para investigação. A elaboração dos parâmetros foi realizada em função da leitura do capítulo referente ao conteúdo escolhido presente nos livros selecionados e de outras referências, como Rodrigues e Dalcin (2014).

$\mathrm{Na}$ sequência, foi realizada a pesquisa do conhecimento, que se refere à fundamentação matemática, baseada em Neto (2013).A quinta fase da análise foi o planejamento da proposta didática a ser implementada, tendo como base a pesquisa do conhecimento e a análise crítica do material didático.O diagrama 1 ilustra os processos realizados no $1^{\circ}$ momento da pesquisa. 


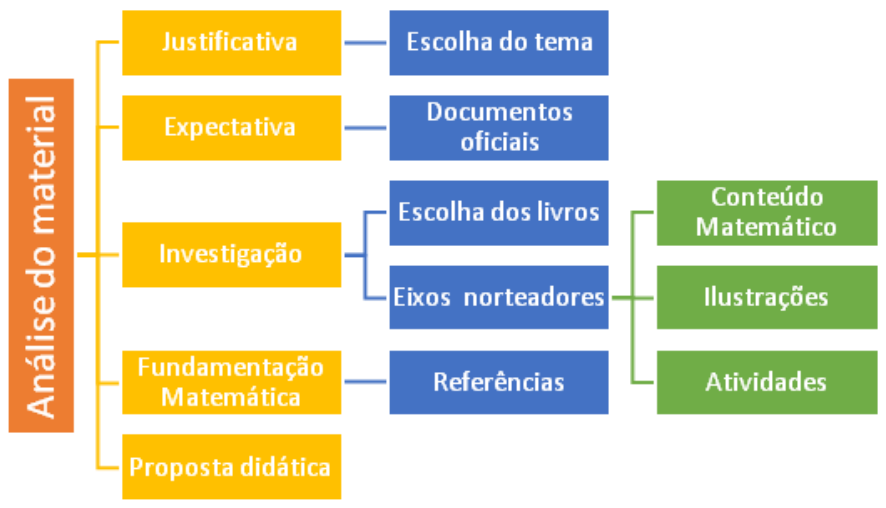

Diagrama 1- processos presentes na primeira etapa

O segundo momento da pesquisa foi a implementação da proposta didática alternativa para trabalhar Teorema de Tales na educação básica. Essa foi aplicada a duas turmas (uma do turno da manhã e outra do turno da tarde) do terceiro ano do ensino médio da Escola Estadual de um município no interior do Rio Grande do Sul. Observase que essa é a única escola desse nível de escolaridade no município escolhido. Para a implementação da proposta, foram realizados três encontros de duas horas cada um. Ao todo, participaram do estudo 36 alunos, separados em grupos de três a cinco estudantes. Identificou-se os grupos com letras do alfabeto, ordenadas de A até $\mathrm{H}$, para preservar a identidade dos participantes.

\section{ANÁLISE DO MATERIAL DIDÁTICO}

$\mathrm{Na}$ sequência, apresenta-se o detalhamento de cada uma das fases da análise do material didático escolhido, conforme apresentado no item anterior. Justifica-se o não uso de imagens ilustrativas, por uma questão de direitos autorais.

\subsection{JUSTIFICATIVA}

Pensado nas dificuldades que os alunos do ensino médioenfrentam no estudo da Geometria em geral, em particular da escola estadual em que o primeiro autor deste trabalho atua e constata a partir de sua prática profissional por alguns anos, decidiu-se o nível de escolaridade e a área a ser investigada. Na prática docente, uma das dificuldades ao trabalhar com tópicos de Geometria Espacial foi o pouco (ou nenhum) 
conhecimento dos alunos sobre alguns resultados clássicos de Geometria Plana, entre eles, o Teorema de Tales. Muitos relataram não o terem estudado no ensino fundamental. Dessa forma, foi realizada a escolha desseconteúdo a ser analisado nos livros didáticos.

\section{2. $\quad$ EXPECTATIVA}

Sobre o Teorema de Tales, segundo a Base Nacional Comum Curricular (BNCC) (BRASIL, 2016), o aluno do nono ano do ensino fundamental deverá conseguir entender o conceito de retas paralelas cortadas por transversais, teoremas de proporcionalidade e verificações experimentais. No ensino médio, o aluno deverá compreender o Teorema de Tales e aplicá-lo em demonstrações e na resolução de problemas, incluindo a divisão de segmentos em partes proporcionais.

Já os Parâmetros Curriculares Nacionais (PCN) indicam:

a Geometria é um campo fértil para se trabalhar com situaçõesproblema e é um tema pelo qual os alunos costumam se interessar naturalmente. $\mathrm{O}$ trabalho com noções geométricas contribui para a aprendizagem de números e medidas, pois estimula a criança a observar, perceber semelhanças e diferenças, identificar regularidades e vice-versa(BRASIL, 1997, p.39).

Assim, espera-se que o material didático a ser analisado traga boa motivação, ou seja, alguma situação do cotidiano do aluno em que ele possa refletir sobre a importância do conteúdo a ser estudado. Acredita-se que explicações e demonstrações são necessárias, mas é de fundamental importância propor atividades a partir das quais o aluno possa manipular tanto fisicamente como com o apoio de recursos computacionais. Espera-se que o conteúdo seja apresentado sem a separação em tópicos e que os exercícios sejamcontextualizados, não apenas aplicações de fórmulas, mas desenvolvendo o Teorema com o intuito de mostrar seu significado e sua aplicabilidade. Nas resoluções de exemplos, deve-se explorar diferentes maneiras de desenvolver cada atividade e mostrar que um mesmo exercício tem mais de um caminho para ser solucionado. Se possível, os exercícios devemter relação com outros conteúdos, dentro da Matemática ou fora dela. Espera-se encontrar alguma aplicação do Teorema em 
outras áreas do conhecimento, como em Artes, trazendo obras artísticas que tenham relação com o assunto.

\subsection{INVESTIGAÇÃ̃O}

Conforme citado anteriormente, o tópico Teoremade Tales foi analisado em Bianchini (2015) e Andrini e Vasconcelos(2015)a partir de três eixos norteadores: Conteúdo matemático; Ilustrações; Atividades Propostas.

Para resumir o processo de análise, no Quadro 1, apresenta-se a comparação realizada nos eixos definidos, levando em consideração os parâmetros presentes (ou ausentes) nos dois livros analisados. Esse quadro foi construído no intuito de sintetizar os aspectos positivos e negativos que cada um dos livros apresenta.

Quadro 1 - Quadro comparativo dos livros A e B.

\begin{tabular}{|c|l|c|c|}
\hline \multicolumn{1}{|c|}{ Eixo } & \multicolumn{1}{|c|}{ Parâmetro } & Livro A & Livro B \\
\hline \multirow{4}{*}{ Conteúdo teórico } & Motivação & & $\mathrm{X}$ \\
\cline { 2 - 4 } & Retomada de conteúdos anteriores & & $\mathrm{X}$ \\
\cline { 2 - 4 } & Conceitos matemáticos equivocados & $\mathrm{X}$ & \\
\cline { 2 - 4 } & Demonstração & $\mathrm{X}$ & $\mathrm{X}$ \\
\hline \multirow{4}{*}{$\begin{array}{l}\text { Ilustrações } \\
\text { Atividades } \\
\text { propostas }\end{array}$} & Imbricadas & $\mathrm{X}$ & $\mathrm{X}$ \\
\cline { 2 - 4 } & Visualização & $\mathrm{X}$ & $\mathrm{X}$ \\
\cline { 2 - 4 } & Contextualização & $\mathrm{X}$ & $\mathrm{X}$ \\
\cline { 2 - 4 } & Ornamentais & $\mathrm{X}$ & $\mathrm{X}$ \\
\hline & Resolvidas & & \\
\cline { 2 - 4 } & Fixação & & $\mathrm{X}$ \\
\hline & Aplicação & & \\
\cline { 2 - 4 } & Aprofundamento & & \\
\hline
\end{tabular}

\subsubsection{Conteúdo matemático}

No eixo referente ao conteúdo matemático, partiu-se do princípio (visto as expectativas definidas anteriormente) de que os conteúdosapresentados nos livros didáticos deveriam promover o contato do aluno com o conhecimento disponível, permitindo a compreensão da realidade que o cerca. Procurou-se estabelecer parâmetros de análisevoltados para o conhecimento matemático, correlacionando-o com aspectos 
pedagógicos, comoo grau de cognição, o estímulo à problematização e a contextualização.

Um dos parâmetros visou identificar a motivação existente para introduzir o novo conteúdo. Ainda nesse item, foi analisada a sequência que os conceitos aparecem no texto e se é realizada a retomada dos conteúdos ou não. Em Matemática, este é um aspecto importante, pois, em geral, um conteúdo depende do outro. Além disso, este é um dos critérios utilizados pelo PNLD quando refere que os livros devem apresentar os conceitos com encadeamento lógico, evitando recorrer a conceitos ainda não definidos para introduzir outro conceito. Também foram observados se existiam conceitos matemáticos equivocados, no sentido de verificar se não eram utilizadas definições circulares, se os autores não confundiam tese com hipótese em demonstrações matemáticas, entre outros. No caso do Teorema de Tales, houve a preocupação de verificar como os livros didáticos analisados realizavam (ou não) a demonstração do Teorema. Pode-se verificar que, nos dois materiais, a demonstração foi realizada. Em um dos livros, o autor não prova a validade do Teorema para os conjuntos dos números racionais e irracionais, porém ressalta que não o faz porque a demonstração é muito complicada para o momento. Acredita-se que tal fato não é verdadeiro, pois os alunos desse período (nono ano) já têm informações sobre esses conjuntos e poderiam trabalhar o Teorema nesses universos numéricos. No outro livro, o autor divide o Teorema em casos (o que não é necessário), porém não cita "o caso" de partições racionais e irracionais.

\subsubsection{Ilustrações}

Em geral, ao analisar criticamente os livros didáticos, verificou-se não existir preocupação com as imagens, qual a sua função, se existe a necessidade de aquela ou de outra imagem se fazer presente em determinado momento. É importante que os educadoresreflitam sobre isso, principalmente quando as ilustrações podem ferir ou chamar a atenção para aspectos políticos e ou sociais (RODRIGUES e DALCIN,2014).

Rodrigues e Dalcin (2014) chamam a atenção para tais aspectos embutidos nas imagens, classificando-as em ilustrações que valorizam a prática de consumo, politicamente corretas, preconceituosas e que valorizam o patrimônio cultural. Como 
exemplo,citam-se figuras que tratam da diversidade, de questões de gênero, crenças inadequadas, entre outros.

No que tange à análise das ilustrações (imagens) presentes nos materiais didáticos analisados, foi tomado como base Dalcin (2007), que classificou as imagens encontradas em livros de Matemática em quatro categorias: imbricadas, visualização, contextualização e ornamentais. Segundo a autora,"as imagens imbricadas são aquelas que estão totalmente articuladas ao texto escrito e com a simbologia matemática, de modo que a ausência de tal imagem tornaria o todo do texto inteligível"(p.29). Observase que tanto o livro A quanto o livro B trazem esse tipo de imagem

Dalcin(2007) categorizailustrações como sendo visualização as que articulam o texto escrito e a simbologia matemática, de modo que um elemento complemente o outro. Nos materiais didáticos analisados,percebeu-se fortemente esse tipo de ilustração.

As imagens categorizadas por Dalcin(2007) como de contextualizaçãoseriam aquelas que estariam, de alguma forma, articuladas diretamente ao texto escrito, complementando-o por meio do apelo à imaginação e à capacidade de interpretação do leitor. Observou-se que os dois livros analisados apresentam ilustrações do tipo contextualização no tópico Teorema de Tales. A última categoria apresentada pela autora são as ilustrações ornamentais, que não apresentam vínculo algum, seja com a simbologia matemática ou com o texto escrito, exercendo apenas a função de "quebra de ritmo de leitura", sem influência na aprendizagem do conteúdo matemático em questão. Apenas o livro B apresenta ilustrações ornamentais.

\subsubsection{Atividades propostas nos livros didáticos.}

No ensino de Matemática, realizar um determinado número de atividades ou resolver problemas que necessitam dos conhecimentos ora apresentados são fundamentais, pois o desenvolvimento das capacidades de argumentação e investigação, podem ser estimulados pela realização de tais tarefas.

Obviamente, não se está considerando que os conceitos e definições não sejam importantes; talvez o problema esteja na forma com que são apresentados nos livros e, consequentemente, trabalhados pelos professores. Nesse sentido, propôs-se uma análise das atividades presentes nos livros didáticos analisados, enfatizando a exploração do 
pensamento matemático, as possibilidades de contextualização, a priorização de aspectos procedimentais em detrimento dos conceituais, ou seja, verificar qual otipo de exercícioque é apresentado (atividades resolvidas, de fixação, de aplicação, de aprofundamento).

Como o próprio nome sugere, as atividades resolvidas são aquelas que apresentam a resolução e, em geral, têm como objetivo servir de modelo para as demais atividades. Os exercícios de fixação são mais comunsos que priorizam os procedimentos (aplicar uma fórmula ou um procedimento). São denominadasatividades de aplicação as que privilegiam algum tipo de experimento prático ou que têm uma abordagem que remete o aluno ao seu cotidiano. Algumas atividades permitem ao aluno elaborar suas próprias conjecturas e privilegiarem o pensamento matemático. Essas tarefas exploratórias foram categorizadas como atividades de aprofundamento. Ambos os livros apresentaram atividades resolvidas e de fixação, apenas o livro $B$ trouxe atividades de aprofundamento e nenhum livro apresentou atividades de aplicação.

\subsection{FUNDAMENTAÇÃO MATEMÁTICA}

Levando em consideração a abstração, a elaboração de novos problemas e os questionamentos, entende-se que "um aspecto especialmente importante [na formação dos estudantes] é a compreensão da Matemática como uma ciência dedutiva e não experimental" (RIPOLL; GIRALDO; RANGEL, 2016, p. 15). Dessa forma, a fundamentação matemática no trabalho desenvolvido foi de extrema importância, pois possibilitou um olhar diferenciado na elaboração da proposta alternativa.

Para essa etapa, foi tomado como referência Neto (2013), que apresenta de uma maneira didática e formal os pré-requisitos necessários ao entendimento do Teorema de Tales, bem como uma demonstração considerando o universo numérico dos números reais.

\section{PROPOSTA DIDÁTICAE RELATO DE SUA IMPLEMENTAÇÃO}

A proposta didáticalevou em consideração as análises realizadas nos livros didáticos; procurou aproveitar algumas tarefas neles encontradas;utilizou os 
conhecimentos matemáticos necessários para a compreensão do teorema e inovou com aplicações distintas daquelas encontradas no material analisado. Assim, a sequência iniciou com o enunciado e a demonstração do Teorema de Tales: "Sejam $r, s$ e $t$ retas paralelas. Escolhemos os pontos

$$
A, A^{\prime} \in r B, B \text { e } \quad C \text {, de modo que }
$$

$A^{\prime}{ }_{s}$ sejam dois ternos de pontos colineares. Então,

$$
\frac{\overline{A B}}{\overline{B C}}=\frac{\overline{A^{y} B^{y}}}{\overline{B^{y} C^{\prime}}}
$$

Para demonstrar esse resultado, foi discutida com os alunos a prova que consta em Neto (2013). Esse autor não separa em casos (como ocorre nos livros didáticos analisados) e, dessa forma, o Teorema é válido para qualquer tipo de partição.

$\mathrm{Na}$ sequência,foram propostos três conjuntos de atividades. O primeiro conjunto, (Atividade 1) tevecomo objetivo verificar a aplicabilidade do Teorema em atividades. Foram propostasduas atividades básicas e diretas.Os alunos não tiveram dificuldade na resolução da Atividade 1, já que ela era simples e exigia apenas o entendimento do Teorema.

O segundo conjunto de atividades teve como objetivo verificar possíveis aplicações do Teorema. Nesse item, foram propostasduas atividades adaptadas dos livros analisados com odiferencial de que a aplicação também foi desenvolvida pelos alunos em sala de aula.

Observa-se que uma horta ou uma maquete poderiam ser situações que envolvessem o conteúdo estudado e aplicáveis pelos alunos. Entretanto, o estudo de anamorfismostambém envolveaplicações do Teorema de Tales e pode ser estudado e produzido por alunos no ambiente escolar.

Oterceiro conjunto de atividadestevecomo objetivo propor a construção de anamorfismos e a verificação da aplicabilidade do Teorema.Foi proposto para os alunos a criação de figuras anamórficas. Em um primeiro momento, conceituou-se anamorfismo conforme realizado na subseção 3. Em um segundo momento, foi apresentado o exemplo com a palavra PARE (Figura 3) como motivação para a aplicação do Teorema de Tales. 
Nesse sentido, questionou-se os alunos sobre o porquê de letras, setas esímbolos na palavra PARE estarem desproporcionais e alongados verticalmente. As respostas foram discutidas e o Manual Brasileiro de Sinalização de Trânsito (CONTRAN, 2007) foi citado pelo professor. Segundo esse manual, existem algumas restrições de medidas para as alturas das sinalizações (Quadro 2).

Quadro 2 - Restrições de medidas de sinalização.

\begin{tabular}{|l|c|c|}
\hline Velocidade & Área Urbana & Área Rural \\
\hline Menor que $80 \mathbf{~ K m} / \mathbf{h}$ & $1,6 m$ & $2,4 m$ \\
\hline Maior que $80 \mathbf{~ K m} / \mathbf{h}$ & $2,4 m$ & $4 m$ \\
\hline
\end{tabular}

Na sequência, a seguinte atividade foi discutida com os alunos:

AtividadeA (Adaptada de IAVORSKI, 2014): Considere um motorista dirigindo seu veículo em via rural (Figura 4), onde a velocidade permitida seja superior a $80 \mathrm{~km} / \mathrm{h}$. Para esse caso, segundo a regulamentação de trânsito, as letras devem ter altura de $4 \mathrm{~m}$. Supondo que nesse modelo de carro os olhos do motorista ficam a uma altura de 1,6m em relação ao solo, determine a distância que o motorista enxerga a placa sem deformações.

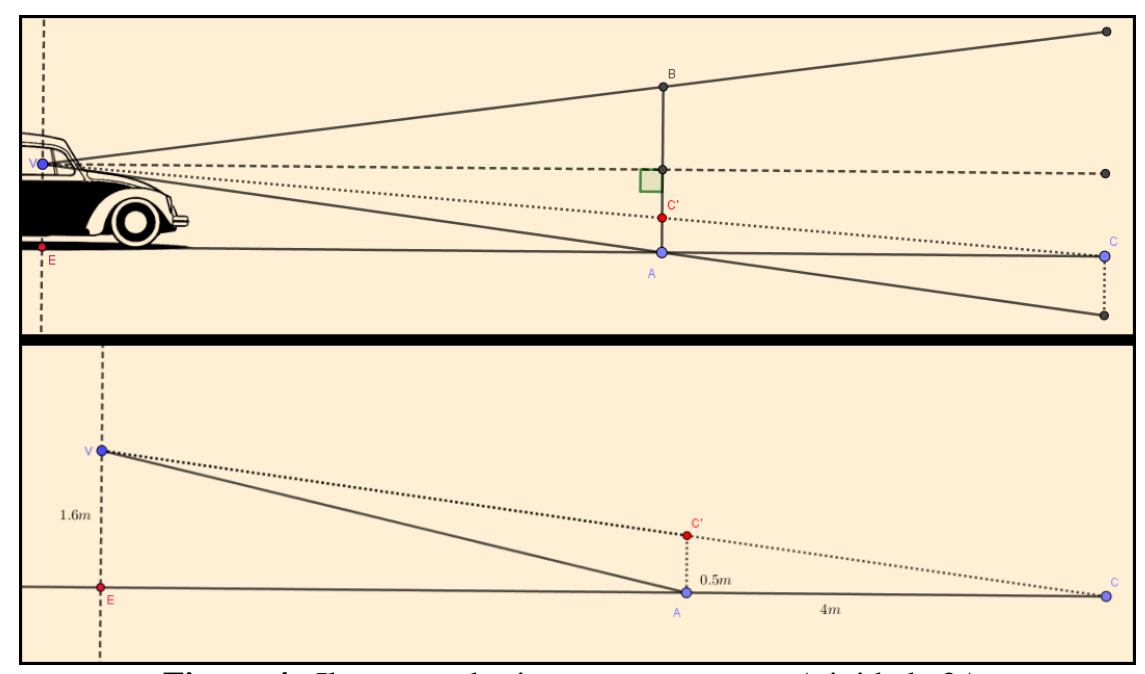

Figura 4- Ilustração da situação proposta na Atividade 3A. 
Para essaatividade, o objetivo é descobrir de qual distância o motorista pode ler a mensagem da forma original. Observou-se dever ser considerado que o motorista está olhando para a frente e que a superfície da estrada naquele trecho é plana e horizontal.

Assim, concluiu-se que a pintura no chão deve ter a sua projeção do segmento $\mathrm{AB}$, pois essa deve ser perpendicular ao eixo do cone visual. Assim, os extremos da projeção serão os pontos $A$ e $C^{\prime}$ (Figura4) e a mensagem terá sua leitura facilitada quando a projeção tiver as medidas originais (50 cm de altura). Conclui-se que, como os segmentos AC' e VE são paralelos e CE é uma transversal, o Teorema de Tales garante que: $\quad \frac{C E}{4}$.Daí, $\quad C E=$.Logo, o motorista enxergará a placa sem deformações a $12,8 m-4 m=$ de distância.

A fim de motivar os alunos para apróxima atividade, foramapresentadosanamorfimos que distorcem duas palavras sobrepostas, uma no sentido vertical e outra no sentido horizontal (Figura 5).

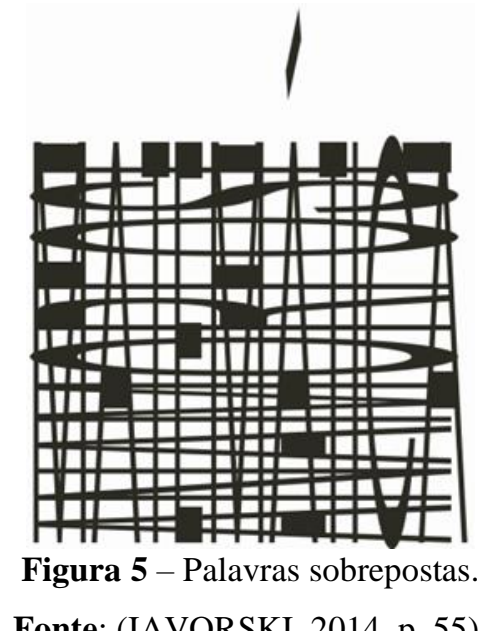

Fonte: (IAVORSKI, 2014, p. 55).

Observou-se que, a princípio, as palavras escritas parecem indecifráveis, mas basta inclinar a folha nos dois sentidos (horizontal e vertical) para que as palavras (mensagens) sejam reveladas (Figura 6).
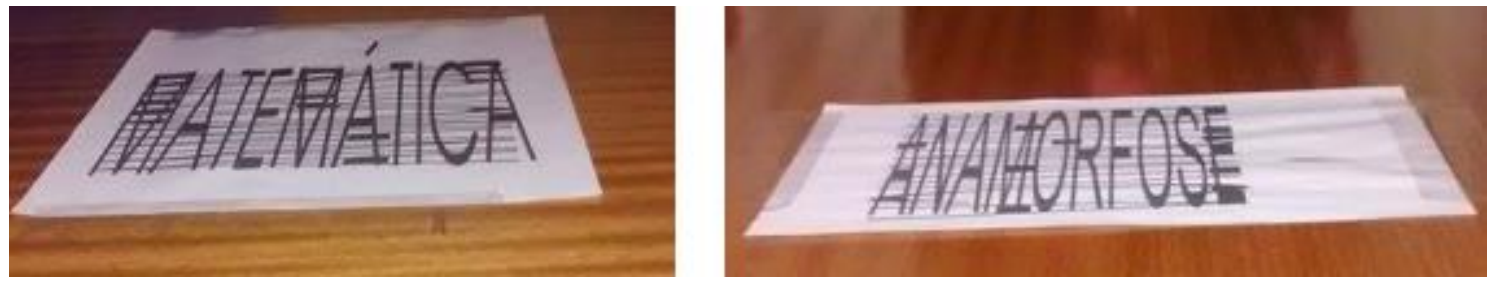
Figura 6 - decifrando o anamorfismo anterior.

Fonte: (IAVORSKI, 2014, p.56).

Na sequência, foi solicitado aos alunos que criassem suas palavras ou frases no papel da mesma forma que os exemplos mostrados pelo professor.

AtividadeB: esta atividade propõe a deformação de mensagens de forma similar com a que é realizada nas sinalizações de trânsito, ou seja: para aumentar a deformação das mensagens, construa uma sobreposta a outra, sendo uma no sentido vertical e outra no sentido horizontal, como no exemplo anterior. O objetivo da atividade é que sejam criadas quaisquer mensagens.

Assim, solicitou-se aos alunos que formassem grupos de três a cinco componentes. O desenvolvimento da atividade se deu em sala de aula, tendo o auxílio do professor.As criações dos alunos se deram em papéis quadriculados e, por meio de cálculos, os próprios educandos concluíram que uma boa aproximação para as letras seria de 2 quadros de largura e 25 quadros de altura. Ao colocar certa angulação com os olhos, o aluno poderia ler sem problemas o que estaria escrito (Figura 7).

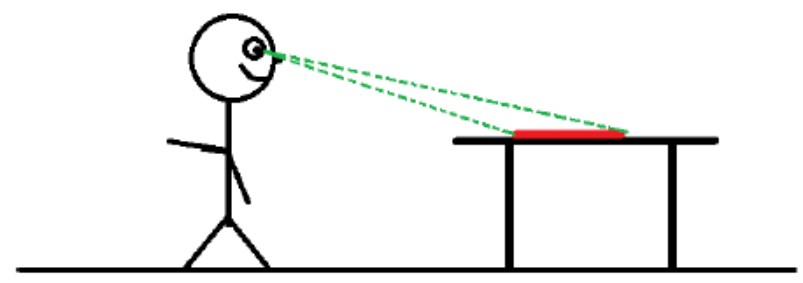

Figura 7- ângulo de visão.

Com auxílio de papel quadriculado, os alunos criaram suas frases e palavras escrevendo gírias próprias, sentimentos e outras palavras, utilizando a técnica aprendida. No que segue, apresenta-se o resultado final de alguns grupos.

A Figura 8 ilustra o trabalho do Grupo A, que escreveu a palavra "The Originals" na horizontal e "Klaus"na vertical. 


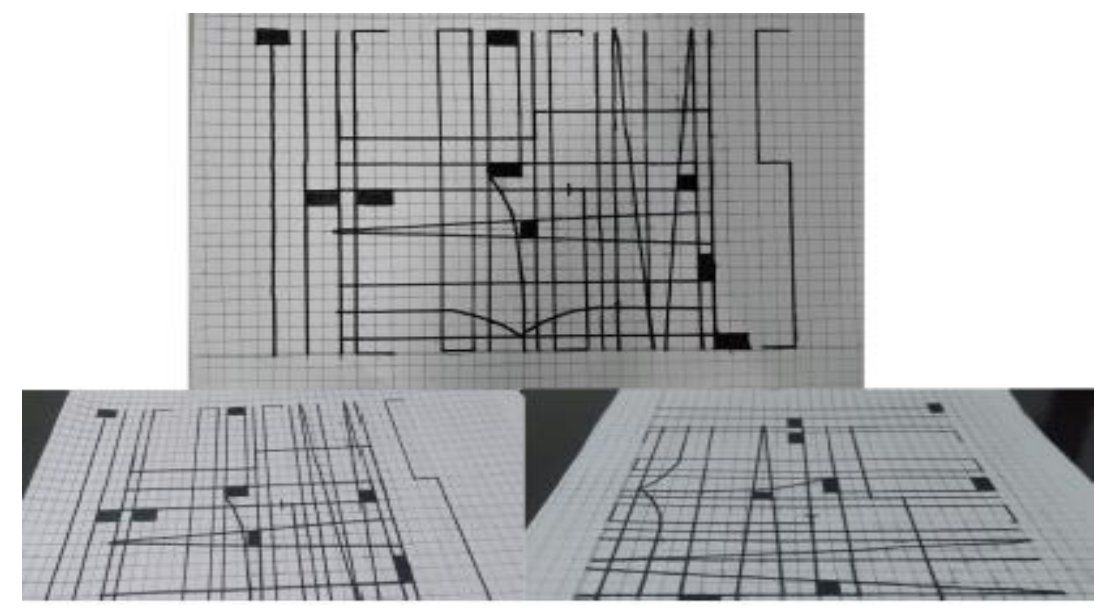

Figura 8 - The Originals (horizontal) eKlaus (vertical).

Fonte: Criação do Grupo A.

O grupo D optou pelas expressões: "Aquela cremosa"e "Ô delícia", conforme ilustra a Figura 9. Observa-se que as expressões são muito informais e fazem parte do dia a dia dos alunos.

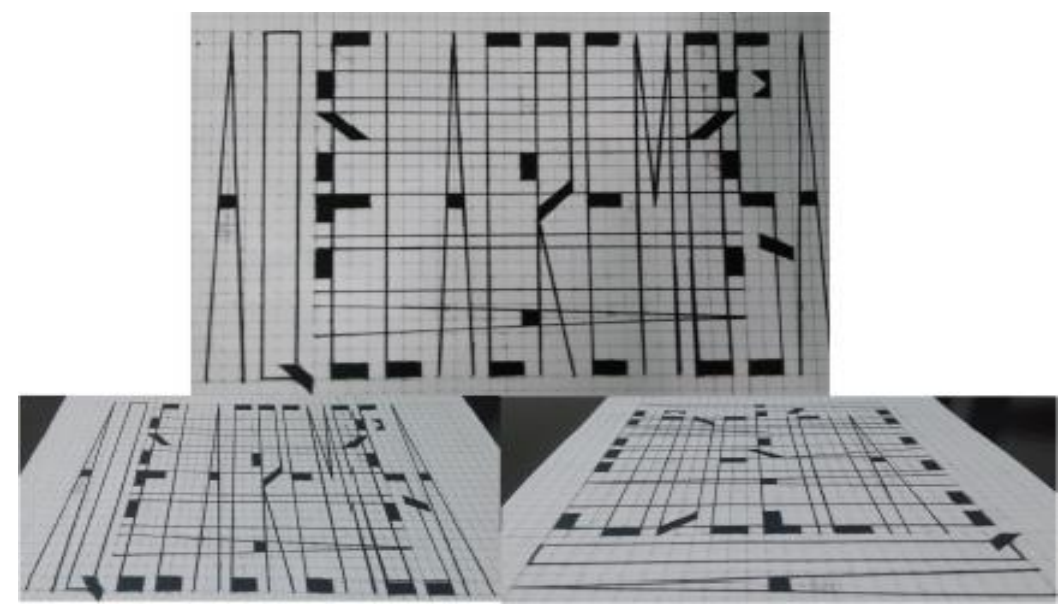

Figura 9 - Aquela cremosa (horizontal)eÔ delícia (vertical).

Fonte: Representações do grupo D

A Figura 10ilustra o trabalho do Grupo E, que escreveu "Wake upandlive" no sentido horizontal e "Life good"no sentido vertical. 


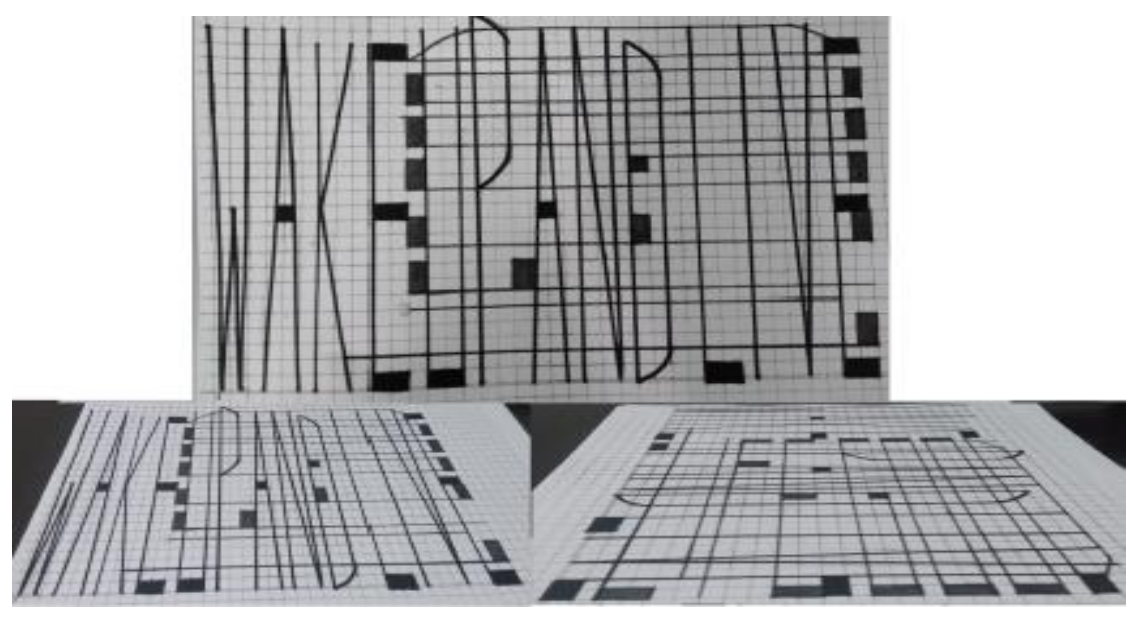

Figura 10 - Wake up and live (horizontal) eLife good (vertical).

Fonte: Grupo E.

Após concluírem, foi questionado aos alunos sobre a validade da atividade com o objetivo de saber se foi significativoutilizar a construção das figuras na compreensão do Teorema de Tales. Muitos alunos gostaram da atividade, alguns disseram nunca terem estudado o Teorema no ensino fundamental, ou não lembravam, mas que a aplicação da atividade foi muito relevante para a compreensão do conteúdo.Alguns falaram que gostariam de mais atividades como a que foi proposta, principalmente em outros conteúdos de Matemática. Entretanto, houve alunos que não gostaram e argumentaram que não se estava trabalhando muito no caderno.

Acredita-se que os anamorfismos e suas construções seja apenas algo para impulsionar o pensamento crítico do aluno de forma que ele perceba à sua volta outros pontos onde o Teorema de Tales possa ser utilizado, não carecendo, necessariamente, que sejam feitos cálculos, mas que seja notada a sua aplicabilidade.

\section{CONSIDERAÇÕES}

Por muitos séculos, a Geometria Euclidiana Plana já é estudada e abordada. Atualmente, percebe-se que tanto no Ensino Básico como no Ensino Superior, inúmeros campos desse conteúdo não são desenvolvidos. Cita-se, por exemplo, a Geometria Fractal, que, assim como o Teorema abordado, tem inúmeras aplicações. O Teorema de Tales é um assunto que, na maioria das vezes, é explorado, porém, pela análise realizada 
nos livros didáticos e pela experiência realizada, ele não é trabalhado de forma que gere interesse nos alunos.

Após a análise dos livros, pôde-se perceber o quanto o Teorema de Tales é utilizado apenas como aplicação de fórmulas matemáticas, sem muito estímulo à criticidade dos alunos no que se refere a situações em que ele possa estar envolvido, mesmo sem a necessidade direta da realização de cálculos. Além disso, foi notável a falha nos conceitos matemáticos nos livros analisados.

Observa-se que se o objetivo dessa análise fosse a escolha do material didático que mais favorecesse o diálogo educativo entre aluno, professor e livro, o eleito seria o Livro B, pois, embora ainda haja algumas falhas e equívocos na demonstração, alguns exercícios e atividades eram mais instigantes. Com trabalho e criatividade do professor, acredita-se que tais exercícios podem se tornar atividades práticas, fazendo com que os alunos tomem gosto pelo que estão aprendendo. O excesso de exercícios mecânicos do Livro A é a sua principal falha. Observa-se que o potencial de ter mais atividades práticas com fixação de fórmulas é o principal intuito desse livro. Somado a isso, há também pequenos deslizes com o desenvolvimento do conteúdo.

Acredita-se que a proposta com abordagem dos anamorfismos foi uma aplicação consistente para o Teorema. Percebeu-se que os alunos puderam construir as expressões e palavras por eles escolhidas, entendendo como o Teorema era aplicado. Pretende-se, em uma próxima oportunidade, criar figuras anamórficas de três dimensões, entendendo a aplicação do Teorema e explorando um pouco mais as habilidades artísticas dos alunos.

\section{REFERÊNCIAS}

ANDRINI, Á.; VASCONCELOS, M. J. Praticando Matemática, 9. [S.1.]: Editora do Brasil, 2015.

BELLO, S.E.L., MAZZEI, L.D. Leitura, escrita e argumentação na Educação Matemática do ensino médio :possibilidades de constituição de significados matemáticos. In: BRANDT, C.F.; MORETTI, M.T. (org.) Ensinar e aprender Matemática: possibilidades para a prática educativa. Ponta Grossa : Ed. UEPG, 2016, pp.119-131 
BIANCHINI, E. Matemática Bianchini, 9. [S.1.]: Moderna, 2015.

BICUDO, M.A.V. Pesquisa Qualitativa e Pesquisa Quantitativa segundo a abordagem fenomenológica. In:BORBA, Marcelo de C. et al. Pesquisa qualitativa em educação matemática. Belo Horizonte: Autêntica, 2004, pp. 99-112

BRASIL. Parâmetros Curriculares Nacionais. Ministério da Educação.Secretaria da Educação Básica, 1997. Disponível em: <http://portal.mec.gov.br/ seb/arquivos/pdf/livro01.pdf >. Acesso em: 16 nov. 2018.

Base nacional comum curricular.Ministério da Educação. Secretaria da Educação Básica, 2016. Disponível em: <http://basenacionalcomum.mec. gov.br/download-da-bncc>. Acesso em: 16 nov. 2018.

MEC. Decreto n $^{\circ} 9.099$, de 18 de julho de 2017 que dispõe sobre o Programa Nacional do Livro e do Material Didático. 2017.

COELHO, M. N.; LIMA, J. P. d.; VIEIRA, S. M. Uma transformação matemática para aprodução de imagens anamórficas cônicas. Revista do Professor de Matemática, SBM, v. 18, n. 95, 2018.

CONTRAN. Manual brasileiro de sinalização de trânsito. Brasília: Conselho Nacional de Trânsito, 2007.

DALCIN, Andreia. Um olhar sobre o paradidático de matemática. Zetetike, v. 15, n. 1, p. 25-36, 2007. .

FLORES, M.; ARAÚJO, A.; FIGUEIREDO, M. Anamorfoses e outras tecnologias imersivas no contexto da educação artística. In: COLÓQUIO DESAFIOS CURRICULARES E PEDAGÓGICOS NA FORMAÇÃO DE PROFESSORES, 2017, Minho. Anais...Minho: Universidade do Minho. Instituto de Educação. Centro de Investigação em Estudos da Criança, 2017, p. 243-250.

FREITAG, B.; MOTTA, V. R.; COSTA, W. F. O estado da arte do livro didático no Brasil. Rede Latino-Americana de Informação e Documentação em Educação, 1987.

GIL, Antonio Carlos. Como elaborar projetos de pesquisa. São Paulo, v. 5, n. 61, p. 1617, 2002.

IAVORSKI, C. Ensinando conteúdos matemáticos usando anamorfose.Universidade Federal Tecnológica do Paraná, Curitiba, 2014.

MOTA, L. Anamorfose a perspectiva da mentira. Blog Cutedrop, 2011.

NETO, A. C. M. Geometria. Rio de Janeiro: SBM, 2013. 
NÚÑEZ, I. B.et al. A seleção dos livros didáticos: um saber necessário ao professor. O caso do ensino de Ciências. Revista Iberoamericana de Educación, v. 33, n. 1, p. 1$11,2003$.

PRIBERAM, D. Dicionário Priberamda Língua Portuguesa, 2010. Disponível em: <https://dicionario.priberam.org/>. Acesso em: 19 nov. 2018.

RIPOLL, C.; RANGEL, L.; GIRALDO, V. Livro do professor de matemática na Educação Básica: números inteiros. Rio de Janeiro: SBM, 2016.

RODRIGUES, A. C.T., DALCIN, A. O que as imagens dos livros didáticos de matemática nos dizem sobre multiculturalismo?Educação Matemática Pesquisa, v. 16, n. 2,p. 459-478, 2014.

ROSA, Flavia Goulart Mota Garcia; ODDONE, Nanci E. Políticas públicas para o livro, leitura e biblioteca. Ciência da Informação, v. 35, n. 3, 2006. 